\title{
Parotid Gland Atrophy in Patients with Chronic Trigeminal Nerve Denervation
}

\author{
E. Raz, L. Saba, M. Hagiwara, L.C. Hygino de Cruz, Jr, P.M. Som, and G.M. Fatterpekar
}

\begin{abstract}
BACKGROUND AND PURPOSE: Trigeminal nerve injury or dysfunction is associated with denervation atrophy of muscles innervated by the mandibular branch of the trigeminal nerve. The purpose of our study was to evaluate the association between chronic $\mathrm{CN} V$ denervation and parotid gland atrophy.
\end{abstract}

MATERIALS AND METHODS: Twenty-six patients with chronic masticator muscle atrophy were retrospectively identified and evaluated for the presence of ipsilateral parotid gland atrophy. Twenty-six age-matched control subjects with no clinical or imaging evidence of chronic masticator space atrophy were also identified. Segmentation of the parotid gland was performed to calculate a parotid asymmetry index. The Fisher exact test and $t$ test were respectively used to determine the correlation between parotid gland atrophy and ipsilateral masticator muscle atrophy and to evaluate any difference in the size of the involved parotid gland when compared with that in the control subjects.

RESULTS: Ipsilateral parotid gland atrophy was seen in 9/26 (42.8\%) patients with fatty replacement of the masticator group of muscles, suggesting a correlation between parotid gland atrophy and $C N V$ denervation $(P<.001)$. The parotid asymmetry index was significantly different in patients with $C N \vee$ denervation $(0.59 \pm 0.25)$ compared with control subjects $(0.92 \pm 0.03)(P<.001)$.

CONCLUSIONS: Ipsilateral parotid gland atrophy can accompany chronic CN V denervation change, and its clinical significance remains to be determined.

ABBREVIATION: CN V = fifth cranial nerve

C ranial nerve $V$ injury or dysfunction is associated with denervation atrophy of muscles innervated by the mandibular branch of the trigeminal nerve, including the masseter, temporalis, medial pterygoid, lateral pterygoid, mylohyoid, tensor tympani, tensor veli palatini, and the anterior belly of the digastric muscles. Imaging characteristics of CN V denervation have been extensively reported. ${ }^{1,2}$ Only a single clinical case report, however, describes ipsilateral parotid gland atrophy related to trigeminal nerve injury after trauma. ${ }^{3}$ Parotid gland atrophy has been de-

Received May 12, 2012; accepted after revision July 9.

From the Department of Radiology (E.R., M.H., G.M.F.), New York University School of Medicine, New York, New York; Department of Radiology (L.S.), Azienda Ospedaliero Universitaria, Cagliari, Italy; Department of Radiology (L.C.H.d.C.), Clínica de Diagnóstico por Imagem Multi-Imagem, Rio de Janeiro, Brazil; and Department of Radiology (P.M.S.), Mount Sinai Medical Center, New York, New York.

Paper previously presented at: 50th Annual Meeting of the American Society of Neuroradiology and the Foundation of the ASNR Symposium, April 21-26, 2012; New York, New York.

Please address correspondence to Eytan Raz, MD, Department of Radiology, New York University School of Medicine, 660 First Ave, 2nd Floor, New York, NY 10016; e-mail: eytan.raz@gmail.com

http://dx.doi.org/10.3174/ajnr.A3290 scribed in animal models after sectioning the auriculotemporal nerve ${ }^{4}$ and after otic ganglionectomy. ${ }^{5}$ The purpose of our study was to evaluate the association between parotid gland atrophy and $\mathrm{CN} V$ denervation atrophy.

\section{MATERIALS AND METHODS}

Approval for this retrospective study was obtained from the investigations review board of NYU Langone Medical Center. The study was conducted in Health Insurance Portability and Accountability Act-compliant fashion, and the need for informed consent was waived.

Patients included in this study were identified from the electronic medical records and imaging reports from 2 institutions spanning a 3-year period (from November 2008 through November 2011). Key terms used to conduct the search included "masticator space atrophy" or "denervation atrophy" or "atrophy muscles of mastication" or "trigeminal nerve denervation." Once these cases were identified, images were reviewed by a board-certified neuroradiologist for radiologic evidence of chronic $\mathrm{CN}$ V denervation change. Only patients 
Table 1: List of patients with trigeminal nerve denervation

\begin{tabular}{|c|c|c|c|c|}
\hline Disease & Sex & $\begin{array}{l}\text { Age } \\
\text { (yr) }\end{array}$ & $\begin{array}{l}\text { Atrophy } \\
\text { Parotid }\end{array}$ & Side \\
\hline $\begin{array}{l}\text { Nasopharyngeal tumor, perineural } \\
\text { spread }\end{array}$ & M & 32 & Yes & Left \\
\hline Melanoma cheek, perineural spread & M & 41 & Yes & Left \\
\hline Trigeminal nerve schwannoma & $\mathrm{F}$ & 46 & Yes & Left \\
\hline Idiopathic & M & 55 & Yes & Right \\
\hline Metastatic cancer in masticator space & $\mathrm{F}$ & 29 & Yes & Right \\
\hline Trigeminal nerve schwannoma & M & 38 & Yes & Left \\
\hline Trigeminal nerve schwannoma & $\mathrm{F}$ & 42 & Yes & Right \\
\hline Trauma & M & 51 & Yes & Right \\
\hline Meningioma & $\mathrm{F}$ & 59 & Yes & Left \\
\hline Idiopathic & $\mathrm{F}$ & 47 & Yes & Left \\
\hline Idiopathic & M & 29 & Yes & Right \\
\hline Trauma & M & 26 & No & Left \\
\hline $\begin{array}{l}\text { Nasopharyngeal tumor, perineural } \\
\text { spread }\end{array}$ & M & 45 & No & Left \\
\hline Trigeminal nerve schwannoma & $\mathrm{F}$ & 38 & No & Left \\
\hline Idiopathic & M & 29 & No & Right \\
\hline Trigeminal nerve schwannoma & $\mathrm{F}$ & 38 & No & Right \\
\hline Trauma & M & 53 & No & Left \\
\hline Idiopathic & M & 54 & No & Left \\
\hline Meningioma & M & 64 & No & Right \\
\hline Meningioma & $\mathrm{F}$ & 47 & No & Left \\
\hline Trigeminal nerve schwannoma & M & 32 & No & Right \\
\hline $\begin{array}{l}\text { Nasopharyngeal tumor, perineural } \\
\text { spread }\end{array}$ & $\mathrm{F}$ & 43 & No & Left \\
\hline Meningioma & $M$ & 64 & No & Left \\
\hline Idiopathic & $\mathrm{F}$ & 65 & No & Right \\
\hline Idiopathic & $M$ & 54 & No & Left \\
\hline Meningioma & $\mathrm{F}$ & 24 & No & Left \\
\hline
\end{tabular}

with MR imaging studies demonstrating chronic masticator space atrophy were included.

Patients with systemic conditions known to cause masticator muscle atrophy, including myasthenia gravis, polymyositis, progressive systemic sclerosis, or rheumatoid arthritis; patients who underwent radiation therapy to the head and neck region; and patients with glossopharyngeal nerve lesions $(n=7)$ were excluded from the study. On the basis of these inclusion and exclusion criteria, 26 cases of masticator space muscle atrophy were identified ( 15 men, 11 women; mean age, $44.0 \pm 12.2$ years). The patient data and the causes of trigeminal nerve denervation are listed in Table 1. A cohort of 26 age-matched individuals referred for trauma with normal findings on MR imaging of the brain and no evidence for $\mathrm{CN} \mathrm{V}$ denervation based on clinical and imaging evaluation were included as healthy controls.

\section{Image Evaluation}

Two board-certified neuroradiologists qualitatively assessed the patient and control population for atrophy of the masticator group of muscles and associated atrophy of the ipsilateral parotid gland; in cases of discordance, evaluation was done by consensus. Atrophy was strictly defined as loss of volume with associated fatty replacement change. Any asymmetry in size without associated fatty replacement change was not considered atrophy. In addition, a quantitative analysis was also performed on the workstation assessing the parotid gland size on a single axial image at the level of the mastoid tip and a measure of the area in square centimeters was obtained for each side (Fig 1).

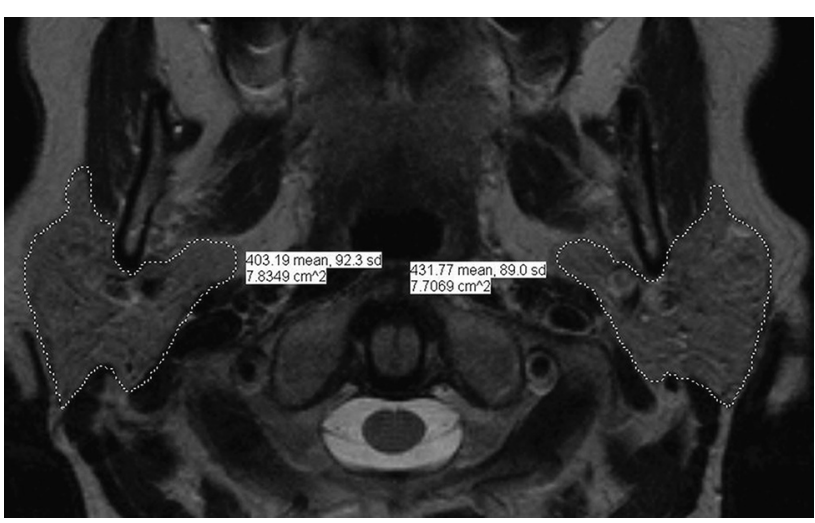

FIG 1. Axial image at the level of the mastoid tip of a healthy control demonstrating the parotid segmentation analysis. This quantitative analysis was performed assessing the parotid gland size to obtain a measure of the area in square centimeters for both sides.

Table 2: $2 \times 2$ Contingency table ${ }^{\mathrm{a}}$

\begin{tabular}{lccc}
\hline & D & ND & Total \\
\hline PA & 9 & 3 & 12 \\
NP & 17 & 75 & 92 \\
Total & 26 & 78 & 104 \\
\hline
\end{tabular}

Note:- D indicates trigeminal denervation; ND, nontrigeminal denervation; PA, parotid atrophy; NP, normal parotid.

${ }^{a}$ Fisher exact test for categoric data.

\section{Statistical Analysis}

For the qualitative evaluation, each side of the face was considered a different statistical unit; a 2-tailed Fisher exact test for categoric data was then used to determine the correlation between atrophy of the parotid gland ipsilateral to the masticator space atrophy (qualitative evaluation). For the quantitative evaluation, the ratio between the size of parotid gland on the side of denervation and the contralateral side was calculated to obtain the parotid gland asymmetry index. For each control, the ratio between the size of the 2 parotid glands was calculated to obtain the parotid gland asymmetry index. The ratios between the 2 groups were then compared by using a nonpaired Student $t$ test after having tested for normality by using a Kolmogorov-Smirnov test.

\section{RESULTS}

Ipsilateral parotid gland volume loss was seen in 9 of the 26 patients $(42.3 \%)$, without any discordance between the 2 readers. Each patient with CN V denervation atrophy $(n=26)$ and each healthy control $(n=26)$ contributed 2 statistical units, 1 for each side of the face, for a total of 104 [2 $\times(26+26)]$ evaluated sides. A $2 \times 2$ contingency table (Table 2 ), by using the Fisher exact test, suggests that this correlation between the parotid gland volume loss and CN V denervation is significant $(P<.001)$.

The mean parotid area in the healthy control population was $5.42 \pm 1.74 \mathrm{~cm}^{2}$ on the right and $5.59 \pm 1.91 \mathrm{~cm}^{2}$ on the left side. In patients, the mean parotid area was $5.54 \pm 2.15 \mathrm{~cm}^{2}$ on the normal side and $3.41 \pm 2.03 \mathrm{~cm}^{2}$ on the denervated side. A KolmogorovSmirnov test analysis demonstrated the mean parotid asymmetry index to be a normal parameter in both the patients $(P=.471)$ and control subjects $(P=.901)$, allowing us to compare the 2 groups by using a Student $t$ test. Quantitative evaluation demonstrated a significant difference between the mean parotid asymmetry index of patients with total fatty replacement $(0.59 \pm 0.25)$ and the mean pa- 

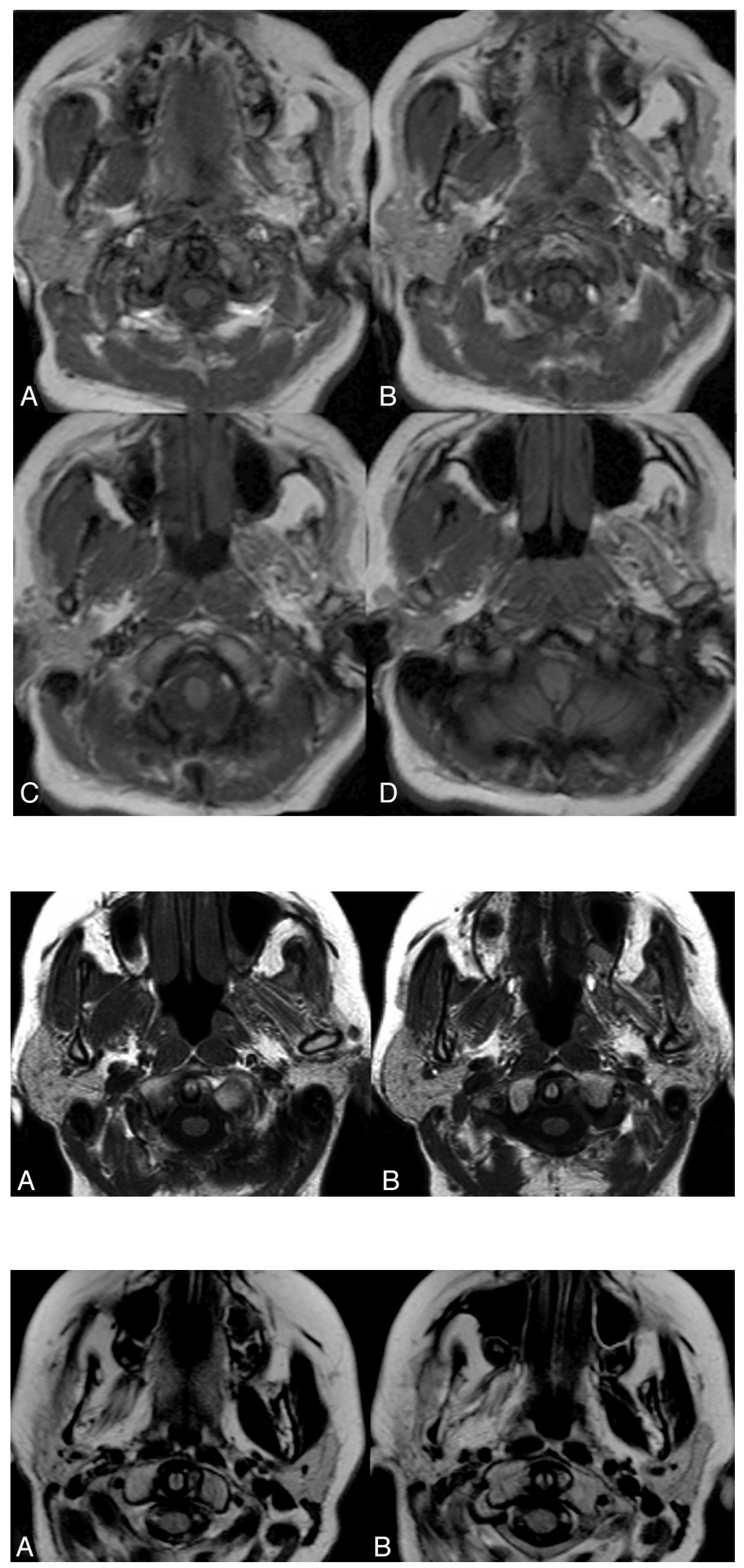

FIG 4. Axial TTWI in a patient with right trigeminal schwannoma. Note the atrophy of the right masticator group of muscles, consistent with trigeminal nerve denervation and atrophy of the ipsilateral parotid gland.
FIG 2. Axial TIWI through the skull base demonstrating left trigeminal nerve denervation and atrophy of the ipsilateral left masticator group of muscles. Note that the left parotid gland is markedly atrophic. The right masticator group of muscles and right parotid gland are unremarkable.

FIG 3. Axial TIWI in another patient with a left petroclival meningioma demonstrates imaging findings consistent with left trigeminal nerve denervation. Note the atrophy of the ipsilateral parotid gland. 
rotid asymmetry index of healthy controls $(0.93 \pm 0.03)(P<.001)$. Pertinent cases are illustrated in Figs 2-4.

\section{DISCUSSION}

We observed a correlation between atrophy of the parotid gland and masticator muscle atrophy secondary to chronic denervation of the trigeminal nerve.

Parotid gland atrophy has been described experimentally in animals after sectioning the auriculotemporal nerve ${ }^{4}$ and after otic ganglionectomy, ${ }^{5}$ and also in humans following sectioning of the parasympathetic preganglionic fibers in the tympanum (tympanic neurectomy), a procedure that has been used as therapy for chronic parotitis. ${ }^{6}$ A single clinical case report describes a case of parotid gland atrophy related to trigeminal nerve injury after trauma. ${ }^{3}$ Otherwise, the effect of trigeminal denervation on the parotid gland in humans has not been studied.

The parotid gland receives its parasympathetic innervation from the fibers of the ninth cranial nerve (glossopharyngeal nerve). After passing through the tympanic cavity and synapsing in the otic ganglion, the postganglionic glossopharyngeal nerve fibers join the auriculotemporal nerve, a ramus arising from the third branch of the trigeminal nerve, to reach the parotid gland. ${ }^{7}$ The auriculotemporal nerve carries sensory nerve fibers to the parotid gland, in addition to the adjacent superficial temporal region, auricle, tympanic membrane, external auditory canal, and the temporomandibular joint. ${ }^{8,9}$ The literature also mentions that the auriculotemporal nerve innervates the parotid gland with nerve fibers from the trigeminal ganglion via substance $\mathrm{P}$-containing neurons. ${ }^{10}$ In this context, we hypothesize that an underlying pathology present in the trigeminal nerve can potentially progress to the auriculotemporal nerve, thus causing parotid atrophy.

Another hypothesis is that the atrophy results from lack of use of the masticator muscles of the ipsilateral side, resulting in a secondary lack of salivation on the same side. This has been termed "ex non usu" and is likely related to the masticatory-salivary reflex, which is known to be a unilateral reflex. ${ }^{11}$ Salivation is stimulated by oral gustatory receptors or mechanoreceptors. The chewing movements and chewing force control the parotid secretion through ipsilateral periodontal receptors and oral mucosal mechanoreceptors. ${ }^{12-15}$ Hence, a decrease in the force of the masticator muscles decreases secretion of saliva through the masticatory-salivary reflex. ${ }^{11-13}$ Because occlusive force on the masticator muscle atrophy side is expected to be lower, this could lead to a reduced masticatory-parotid reflex on the same side and to consequent disuse atrophy of the parotid gland. Patients with a unilateral stroke have a reduced masticatory-salivary reflex ipsilateral to the side of hemiparesis. ${ }^{16}$ Moreover, this can be accentuated by the lack of sensory input from the ipsilateral side of the face, driven by the trigeminal nerve and likely reduced in the setting of $\mathrm{CN}$ V denervation. ${ }^{13}$

Relevant clinical correlation of the finding warrants further investigation, though parotid gland atrophy does result in decreased salivary gland secretion leading to xerostomia, lip dryness, and a fragile and atrophied oral mucosa, with difficulty in clear speech articulation and eating, as well as associated halitosis. A decrease in saliva flow can also reduce clearance of saliva and thereby increase the risk of dental plaque. ${ }^{17}$

Limitations of this study include the retrospective design.
Moreover, the occurrence of parotid atrophy was seen in only a subset of the patients with CN V denervation and not in all the patients, because such atrophy of the parotid gland is influenced by the chronicity of the event, which could not be evaluated because the duration of the underlying disease was not known in our patients. Another limitation is that we performed the evaluation of parotid gland size on a single section at the level of the mastoid tip, a relative weakness in the study design, though a volumetric evaluation would be optimal.

\section{CONCLUSIONS}

Parotid gland atrophy can accompany chronic denervation atrophy of the muscles innervated by the third division of the trigeminal nerve. This was seen in only a subset of patients, and its clinical significance remains to be determined.

Disclosures: Girish M. Fatterpekar-UNRELATED: Royalties: Elsevier Publishing Group for 2 textbooks, Teaching File Head and Neck and Teaching File Brain and Spine.

\section{REFERENCES}

1. Russo CP, Smoker WR, Weissman JL. MR appearance of trigeminal and hypoglossal motor denervation. AJNR Am J Neuroradiol 1997;18:1375-83

2. Smoker WR, Reede DL. Denervation atrophy of motor cranial nerves. Neuroimaging Clin North Am 2008;18:387-411, xi

3. Markitziu A, Reches A. Oro-facial trophic changes induced by nerve injury. Int J Oral Surg 1982;11:69-72

4. Emmelin N. Degeneration secretion from parotid glands after section of the auriculotemporal nerves at different levels. J Physiol 1968;195:407-18

5. Khosravani N, Ekman R, Ekström J. The peptidergic innervation of the rat parotid gland: effects of section of the auriculo-temporal nerve and/or of otic ganglionectomy. Arch Oral Biol 2008;53:238-42

6. Mandour MA, Helmi AM, El-Sheikh MM, et al. Effect of tympanic neurectomy on human parotid salivary gland: histopathologic, histochemical, and clinical study. Arch Otolaryngol 1977;103:338-41

7. Porto AF, Proud GO, Norris CW, et al. Secretory innervation of the parotid gland. Otolaryngol Head Neck Surg 1981;89:16-19

8. Du Toit DF. Auriculo-temporal nerve: clinicopathological relevance to facial-maxillary practice. $S A D J 2003 ; 58: 62-63$

9. Gray H, Bannister LH, Berry MM, et al. Gray's Anatomy: The Anatomical Basis of Medicine and Surgery. Oxford, UK: Churchill Livingstone Elsevier; 1995:2092

10. Sharkey KA, Templeton D. Substance $\mathbf{P}$ in the rat parotid gland: evidence for a dual origin from the otic and trigeminal ganglia. Brain Res 1984;304:392-96

11. Jensen Kjeilen JC, Brodin P, Aars H, et al. Parotid salivary flow in response to mechanical and gustatory stimulation in man. Acta Physiol Scand 1987;131:169-75

12. Anderson DJ, Hector MP, Linden RW. The effects of unilateral and bilateral chewing, empty clenching and simulated bruxism, on the masticatory-parotid salivary reflex in man. Exp Physiol 1996;81:305-12

13. Hector MP, Linden RW. The possible role of periodontal mechanoreceptors in the control of parotid secretion in man. Q J Exp Physiol 1987;72:285-301

14. Scott BJ, Hassanwalia R, Linden RW. The masticatory-parotid salivary reflex in edentulous subjects. J Oral Rehabil 1998;25:28-33

15. Wolff A, Ofer S, Raviv M, et al. The flow rate of whole and submandibular/sublingual gland saliva in patients receiving replacement complete dentures. J Oral Rehabil 2004;31:340-43

16. Kawasaka T, Shimodozono M, Ogata A, et al. Salivary secretion and occlusal force in patients with unilateral cerebral stroke. Int $\mathrm{J} \mathrm{Neu}$ rosci 2010;120:355-60

17. Dodds MW, Johnson DA, Yeh C.-K. Health benefits of saliva: a review. J Dent 2005;33:223-33 